\title{
The evaluation and effectiveness of school based assessment among science teachers in Malaysia using CIPP Model
}

\author{
Norazilawati Abdullah*, Norwaliza Abdul Wahab, Noraini Mohamed Noh, Eftah Moh Abdullah, Aslina Ahmad
}

Faculty of Education and Human Development, Sultan Idris Education University, Tanjung Malim, Malaysia

\section{A R T I C LE IN F O}

\section{Article history:}

Received 20 August 2016

Received in revised form

15 October 2016

Accepted 27 October 2016

\section{Keywords:}

Evaluation

Effectiveness

CIPP model

School based assessment (SBA)

Science teachers

\begin{abstract}
A B S T R A C T
The purpose of this study is to identify the effectiveness of School Based Assessment (SBA) in science subject among secondary science teachers using CIPP Model. It also investigates the evaluation of science teachers' regarding the advantages and disadvantages of SBA. A total of 112 science teachers from 21 secondary schools in Batang Padang District, Perak, Malaysia were involved in this survey. The data from the questionnaires and survey were analyzed using descriptive statistics and statistical inference. Frequency distribution with mean scores and percentages and Pearson correlation analysis were used. Results showed that the dimensions of context, input and product are at a moderate level while the level of process dimension is high. Hypothesis is also accepted, there is no significant relationship between the level of dimensional context, input, process and product in the implementation of SBA with teaching experience. Analysis of the interviews showed that most respondents agree that there are advantages of SBA, thus is suitable with the aim of Malaysia to create a world-class human capital. In conclusion, this study provides new contributions to teachers in Malaysia to implement SBA effectively through training, courses, monitoring and ongoing support from Ministry Of Education.
\end{abstract}

(C) 2016 The Authors. Published by IASE. This is an open access article under the CC BY-NC-ND license (http://creativecommons.org/licenses/by-nc-nd/4.0/).

\section{Introduction}

School-Based Assessment Program (SBA) is another transformation in the education assessment system in Malaysia. It is an alternative assessment system of government by reviewing the existing assessment and evaluation in order to make school not too exam-oriented. School-based assessment system, a fairly new innovation in assessment is an assessment which is conducted by subject teachers in classrooms following the procedures from the Malaysian Examination Syndicates in terms of planning, administration, scoring and reports. Ministry of Education (MOE) has focused on strengthening the system of assessment and evaluation in order to present a more holistic and authentic assessment. It assesses the process and product of teaching and learning. It is considered a holistic assessment because it assesses various aspects of student's development such as their cognitive, affective and psychomotor. This means

\footnotetext{
* Corresponding Author.

Email Address: nora@fppm.upsi.edu.my (N. Abdullah)

https://doi.org/10.21833/ijaas.2016.11.001

2313-626X/@ 2016 The Authors. Published by IASE

This is an open access article under the CC BY-NC-ND license

(http://creativecommons.org/licenses/by-nc-nd/4.0/)
}

that the assessment is important because it can see the overall student achievement that meets the goals of the National Education Philosophy in an effort to establish and develop human capital excellence. Among the goals of SBA is to get an overview of the performance of students in their learning, assess the activities carried out during the process of teaching and learning takes place, get continuous information about the teaching and learning as well as planning and improve teaching and learning (Awang, 2011).

\section{Literature review}

School Based Assessment (SBA) is premised upon the notion that regular, classroom-based assessment provides a reliable indicator of student learning, while also contributing feedback for future learning (Brown and Hirschfeld, 2008). Feedback is a 'continuous, ongoing, and interactive' process (Kouritzin and Vizard, 1999) which involves multiple sources (teachers, peers, friends, and so on) and a variety of forms (visual, written and oral).

According to the Malaysian Examinations Board, SBA is a form of assessment in schools. It is planned and administered systematically. The scores are reported in planned activities in accordance with the procedures laid down by the Malaysian Examination 
Board. SBA is also a combination of school assessment undertaken by teachers as well as confirmation of the appraisers in the National Achievement Centre or the student report based on the competencies they have accessed, understood and skilled (Azhari, 2005). SBA was actually implemented in Malaysia in phases starting in 2003. It involves eleven subjects including science subjects in which students are assessed through practical work assessment. Now SBA was carried out across the board for all subjects in primary and lower secondary. SBA has also given recognition and autonomy to teachers to implement formative and summative assessment in schools. SBA was conducted at the school by teachers in accordance with the procedure and format Malaysian Examination Board (MEB) may prescribe. Teachers need to assess and implement SBA by administering, assessing, and recording suspended and affective achievement of students at the school level (Mahamod et al., 2010).

The success of reforms in education depends on teachers who conduct the assessment. The changes will not happen if teachers are not sure about the need for change and are willing to change the paradigm (Norazilawati et al., 2012). This is because the SBA is a more meaningful assessment, authentic (genuine) already robust (solid). It is hoped that this will result in the assessment of human capital is critical, creative, innovative, competitive and progressive as envisaged by the state.

\section{Problem Statements}

SBA is responsible in testing and assessing students' overall performance from every aspect. Assessment encompasses academic performance, cocurriculum and personality traits while students are undergoing teaching and learning processes. Teachers who are responsible and accountable in conducting SBA process have to adhere to all assessment steps and procedure. However, teachers' lackadaisical attitude in assessment may jeopardize the whole assessment system. Assessment quality could be debated by everyone if there is no monitoring system in place. If this happens, concerns abound pertaining to biasness, transparency and standardization of students' assessment when this practice is hailed as one of important elements in ensuring that students achieve deserving grades throughout teaching and learning. This issue was discussed in a study by Tan (2010) whereby lacking of monitoring will make teachers non-committed and lackadaisical in conducting assessment.

The inability of any school to standardize scores will more or less contribute to disputes amongst parents and teachers. This is due to comparison of scores that is still the tradition of parents to compare their children's success with other people's children. This problem had been discussed in a study by Barak and Shakhman (2008). The schools and teachers frequently neglect a few important processes like monitoring, score validity and others to the extent that SBA implementation leaves an undesirable effect to students. Guidelines set by the MOE in ensuring the quality of SBA should be given emphasis before and during SBA implementation.

After four years of implementation of the SBA in school, the teachers began to complain will have to bear the burden of work and has been a hoax and hot news in the newspapers. Many teachers agree that if the SBA removed. According to Stufflebeam and Shinkfield (2007), rating is a discipline that is very important to ensure a successful program or project. A program or project cannot be said to be successful after its strengths and weaknesses can be detected. Thus corrective measures can be taken and process improvements can be implemented in order for a program to achieve the desired goals.

Therefore, this study was conducted to evaluate the effectiveness of the implementation of the SBA science teachers in secondary schools conducted in terms of context, input, process and product. Ratings (1) The dimension of context (relevance of SBA with the National Education Philosophy, science teachers' attitude and willingness to SBA); (2) The input dimension (knowledge, skills and confidence to run a SBA science teachers, equipment, laboratories, facilities, timetable, training and support principals); (3) the dimensions of the process (teaching and learning strategies for teachers and science teachers how to run SBA to evaluate the work of students); and (4) the dimensions of the product (revenue changes in student achievement and attitudes toward science subject). The second objective is to identify whether there is a correlation between the level of dimensional context, input, process and product implementation for SBA with teaching experience. The third objective is to identify the advantages, weaknesses, challenges and recommendations in realizing the SBA science teacher.

\section{Theoretical framework}

Looking at the few evaluation models, there are many possible theoretical frameworks that could be used in evaluating the system, of which in part depends on the questions and topics of interest. In the case of SBA, we are primarily interested in the effectiveness of the system implementation. This leads us to look at various dimensions of evaluation. For this reason, CIPP evaluation model was chosen as the framework of this study. The CIPP Evaluation Model was developed by (Stufflebeam, 2003) to evaluate any projects, personnel, products, institutions or systems from various disciplines such as education field, housing and community development, transportation safety and military personnel review systems.

Various educational programs have been conducted using this model, such as those related to science and mathematics education, rural education, educational research and development, school improvement, professional development schools and many more (Stufflebeam, 2002). A key characteristic 
of this model is its four dimensions of evaluation context, input, process and product (Stufflebeam, 1971). These four dimensions of evaluation also serve planning, structuring, implementing and recycling decisions respectively. As such, context evaluation involves confirming the present objectives, to modify the existing objectives or develop new ones. Input assesses the strategies, personnel, resources or procedures in achieving the program's objectives, process evaluation is looking at everything related to the implementation of already selected designs, strategies or action plan and product evaluation determines and examines the specific outcomes of the program. Furthermore, it is based on the management-oriented approach which allows managerial decision-makers to get enough information from the evaluators (Hogan, 2007).

The CIPP Evaluation Model is a useful framework for analyzing the interrelationship between the four evaluation dimensions. It is consistent with the definition of operational assessment in this study the evaluation process is a draw, collect and provide useful information to choose alternative decisions for improvement. The level of context, input, process and product can provide important and useful information to plan implementation strategies or action plans for the structuring of a more robust implementation of the SBA in order to achieve its goals:

1. Context evaluation: what are the needs and opportunities? What should be our goals? (SBA Goals)

2. Input evaluation: what are our options? What approaches can we take? How do these approaches compare in terms of resources needed? (SBA Planning)

3. Process evaluation: how is program implementation going? Are we on track? Do we need to adjust? (SBA Evaluation)

4. Product evaluation: what is our success or failures? What has changed as a result of our program? (SBA Results)

Based on the above rationale, the conceptual framework of this research was formed in Fig. 1.

\section{Objectives}

The research conducted to:

1.To evaluate the effectiveness of the implementation of the SBA among science teachers in secondary schools conducted in terms of context, input, process and product.

2. To identify whether there is a correlation between the level of dimensional context, input, process and product implementation for SBA with teaching experience.

3. To identify the advantages, weaknesses, challenges and recommendations in realizing the SBA science teacher.

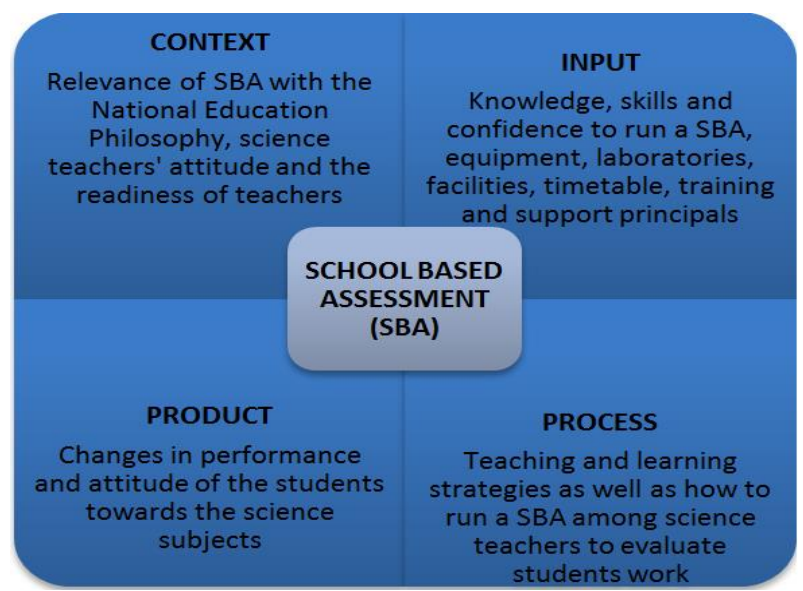

Fig. 1: Theoretical framework

\section{Hypothesis}

Ho1: There is no significant relationship between context, input, process and products in the implementation of the SBA with teachers teaching experience.

\section{Research methodology}

The study used combination of quantitative and qualitative approaches. The quantitative data used questionnaire as instrument consists of two parts. Part A of teacher demographics. Part B consists of 45 items to obtain information on the assessment of the context, input, process and product implementation in schools. Items that are formed in this questionnaire developed by the researchers based on operational definitions for each construct was used in this study and modify the questionnaire adopted by Norazilawati et al. (2012). This questionnaire has been tested for reliability by running a pilot test to 20 teachers. Cronbach's alpha values obtained for each item is between 0.929 to 0.934 . The overall reliability of this study is 0.932 items. This proves that Cronbach alpha reliability index for this study is high.

Qualitative data used interviews questions as an instrument. Interview questions were developed by the researchers to identify advantages, weaknesses, challenges and recommendations for science teachers in the realization of SBA.

Quantitative sample consisted of 112 science teachers form 1 and form 2 who taught at 21 secondary school in Batang Padang District, Perak, Malaysia. While for qualitative sample, only five science teachers interviewed from five schools which is involved in the study. Selection of study participants is intended (purposive sampling) so that the information obtained can give an answer to the research question.

\section{Findings and discussion}

The results were analyzed and discussed by the research objectives. 
Research Objective 1: To evaluate the effectiveness of the implementation of the SBA among science teachers in secondary schools conducted in terms of context, input, process and product:

1. The findings showed that the level of context (relevance of SBA with the National Education Philosophy, science teachers' attitude and the readiness of teachers) in the implementation of the SBA is moderate with overall mean is 3.31 and the standard deviation is 0.885 (Table 1 ).

2. The findings showed that the level of input (knowledge, skills and confidence to run a SBA, equipment, laboratories, facilities, timetable, training and support principals) in the implementation of the SBA is moderate with a mean overall is 3:52 and the standard deviation is 0.900 (Table 2).

3. The findings showed that the level of process (teaching and learning strategies as well as how to run a SBA among science teachers to evaluate student work) in the implementation of SBA is at a high level with the overall mean is 3.81 and the standard deviation is 0.732 (Table 3 ).

4. The findings showed that the level of product (due to changes in performance and attitude of the students towards the science subjects) in the implementation of the SBA are at medium with mean overall is 3.20 and the standard deviation was 0.932 (Table 4).

Table 1: Level of context

\begin{tabular}{|l|c|c|c|}
\hline \multicolumn{1}{|c}{ Item } & Mean & SD & Interpretation \\
\hline 1. Implementation of relevant SBA the current education system in Malaysia. & 3.29 & 1.053 & Medium \\
\hline 2. I clear about the goals and SBA implementation objectives. & 3.65 & 0.767 & Medium \\
\hline 3. SBA reduce pressure on public examinations. & 3.08 & 1.027 & Medium \\
\hline 4. SBA does not charge me. & 2.30 & 0.947 & Low \\
\hline $\begin{array}{l}\text { 5. I get information about SBA objective through the administrator, MOE and the } \\
\text { current website attending courses in services. }\end{array}$ & 4.05 & 0.655 & High \\
\hline $\begin{array}{l}\text { 6. SBA is an assessment system national education guaranteed quality in terms of } \\
\text { legality and reliability, and act towards learning more effective. }\end{array}$ & 3.07 & 0.927 & Medium \\
\hline $\begin{array}{l}\text { 7. SBA control, coordinate and conduct all examinations schools, public examination } \\
\text { and no external examination contrary to government policy and national interest. }\end{array}$ & 3.29 & 0.966 & Medium \\
\hline $\begin{array}{l}\text { 8. SBA help educational system attaining international standards in the field } \\
\text { knowledge, skills and competencies as well as world class leading Assessment by } \\
\text { 2020. }\end{array}$ & 3.39 & 0.989 & Medium \\
\hline $\begin{array}{l}\text { 9. SBA be able to monitor the growth of the students and help to increase the } \\
\text { potential individual. }\end{array}$ & 3.56 & 0.814 & Medium \\
\hline 10. SBA make meaningful reporting about individual learning & 3.42 & 0.790 & Medium \\
\hline Average Score & $\mathbf{3 . 3 1}$ & $\mathbf{0 . 8 8 5}$ & Medium \\
\hline
\end{tabular}

Table 2: Level of input

\begin{tabular}{|l|c|c|c|}
\hline \multicolumn{1}{|c}{ Item } & Mean & SD & Interpretation \\
\hline 11. I have to sign a form The Official Secrets Act 1972 (Act 88) before implement SBA. & 3.25 & 0.953 & Medium \\
\hline 12. I was following training/ course to build instruments of SBA. & 3.21 & 1.255 & Medium \\
\hline 13. I know how to build instruments for assessing students. & 3.33 & 0.980 & Medium \\
\hline 14. I have adapted the instruments with teaching methods. & 3.47 & 0.910 & Medium \\
\hline 15. I should have the current Quality Assurance Guidance Document SBA. & 3.90 & 0.722 & High \\
\hline 16. I mastered On Scoring of SBA. & 3.33 & 0.865 & Medium \\
\hline 17. I am skilled at assessing students eviden . & 3.75 & 0.942 & High \\
\hline 18. I give the exact score, consistent and in accordance to the students. & 3.47 & 0.827 & Medium \\
\hline 19. My scoring of verified and signed by the school administrators. & 3.52 & 0.793 & Medium \\
\hline 20. I always talk to a friend about SBA. & 3.97 & 0.728 & High \\
\hline $\begin{array}{l}\text { 21. Main Committee SBA in my school give many provide exposure and training to } \\
\text { increase the understanding of implement SBA. }\end{array}$ & 3.62 & 0.891 & Medium \\
\hline $\begin{array}{l}\text { 22. My school provides an environment supporting the implementation and SBA } \\
\text { acculturation. }\end{array}$ & 3.47 & 0.889 & Medium \\
\hline $\begin{array}{l}\text { 23. Internet facilities can be accessed properly in school helps me in the } \\
\text { implementation of the SBA. }\end{array}$ & 2.84 & 1.116 & Medium \\
\hline $\begin{array}{l}\text { 24. I prefer Private-owned internet access from accessing the internet in school to } \\
\text { facilitate my assessment of students. }\end{array}$ & 3.89 & 0.961 & High \\
\hline 25. I set up a Daily Lesson Plan containing assessment activities. & 3.83 & 0.678 & High \\
\hline Average score & $\mathbf{3 . 5 2}$ & $\mathbf{0 . 9 0 0}$ & Medium \\
\hline
\end{tabular}

Research Objective 2: To identify whether there is a correlation between the level of dimensional context, input and process and product implementation for SBA with teaching experience.
Correlation between the level of context, input, process and product of the implementation of the SBA with experience in teaching science:

1. Pearson Correlation Analysis Results, in total there are 4 items that shows that there are significant 
relations and 6 items that show there is no significant relationship between the dimensions of the context of the implementation of the SBA with teaching experience teachers. So it can be concluded that there is no significant relationship in the context of the implementation of SBA. For item 1 results obtained from analysis is $[\mathrm{r}=0.141$ $*, p=0.137>0.05]$. Item 2 is $\left[\mathrm{r}=0.171^{*}, \mathrm{p}=0.072\right.$ $>0.05]$. Item 4 is $\left[\mathrm{r}=\operatorname{area}^{*}, \mathrm{p}=0.257>0.05\right]$. For item $8\left[\mathrm{r}=0.128^{*}, \mathrm{p}=0.05>(\mathrm{s})\right]$. Correlation for items 1, 2, 4 and 8 is positive at the level of very low. This shows there is a significant relationship between the contexts of the implementation of the SBA with teachers teaching experience. While for item 3 is $[\mathrm{r}=-0.032 *, \mathrm{p}=0.736>0.0$ Item 5 is $[\mathrm{r}=$ $0.095, \mathrm{p}=0.318>0.05]$. Item 6 is $[\mathrm{r}=-0.070 *, \mathrm{p}=$ $0.461>0.05]$. 5]. Item 7 is $\left[\mathrm{r}=0.75^{*}, \mathrm{p}=0.434>\right.$ $0.05]$. Item 9 is $[\mathrm{r}=0.019, \mathrm{p}=0.840>0.05]$. Item 10 is $\left[\mathrm{r}=-0004^{*}, \mathrm{p}=0.966>0.05\right]$. Item 10 is the $\left[\mathrm{r}=-0004^{*}, \mathrm{p}=0.966>12: 05\right]$. Correlation of items $3,5,6,7,9$ and 10 showed no significant relationship between the contexts of the implementation of SBA with teaching experience.

Table 3: Level of Process

\begin{tabular}{|l|c|c|c|}
\hline \multicolumn{1}{|c}{ Item } & Mean & SD & Interpretation \\
\hline 26. I have a manual guide as references in provides planning assessment. & 3.77 & 0.845 & High \\
\hline 27. The content of the assessment instruments I use Standard Learning. & 3.89 & 0.648 & High \\
\hline $\begin{array}{l}\text { 28. Before undertaking the assessment, I make sure the instruments in } \\
\text { accordance with the level intelligence of students. }\end{array}$ & 3.83 & 0.708 & High \\
\hline 29. Assessment instrument that I use according to a study constructs. & 3.83 & 0.642 & High \\
\hline $\begin{array}{l}\text { 30. I use assessment methods range (observation, oral, and written) whether } \\
\text { formal or informal as appropriate. }\end{array}$ & 4.09 & 0.643 & High \\
\hline 31. I always evaluate the understanding of students in implementing its SBA. & 3.88 & 0.640 & High \\
\hline $\begin{array}{l}\text { 32. I implement the guidance to the students who have not mastered the } \\
\text { standard of learning. }\end{array}$ & 3.89 & 0.751 & High \\
\hline 33. I prepare the student assessment reporting with formative and summative. & 3.85 & 0.655 & High \\
\hline $\begin{array}{l}\text { 34. During the implementation of SBA I believe and confident the production of } \\
\text { good instruments will measure the performance of students. }\end{array}$ & 3.72 & 0.807 & High \\
\hline 35. I always inform the results of assessment to students and parents/guardians. & 3.39 & 0.989 & Medium \\
\hline Average score & $\mathbf{3 . 8 1}$ & $\mathbf{0 . 7 3 2}$ & High \\
\hline
\end{tabular}

Table 4: Level of product

36. I get along with the date and duration set by the MOE in implement SBA.

37. SBA can help improve student achievement.

38. SBA attract students to the contents of the lessons taught.

39. The implementation of the SBA to make students more responsible for their studies.

40. The implementation of the SBA reduces students absences.

41. SBA helps teachers in building a variety of new learning opportunities to students.

42. SBA helps teachers in increasing student assessment practices.

43. SBA helps teachers in developing teachers'professionalism.

44. SBA helps teachers and students willing to discuss problems of learning in an

atmosphere that is not stressed.

45. SBA improve implementation satisfaction, trust and confidence people to the school.

Average score

2. Pearson Correlation Analysis Results, in total there are 4 items that shows that there are significant relations and 11 items that show there is no significant relationship between the inputs in the implementation of the SBA with teachers teaching experience. So it can be concluded that there is no significant relationship the input in the implementation of the SBA with teachers teaching experience. For item 15 results obtained from of analysis is $\left[r=0.126^{*}, p=0.185>0.05\right]$. Item 20 is $\left[r=0.036^{*}, p=0.710>0.05\right]$. Item 22 is $[r=0.145$ *, $\mathrm{p}=0.128>0.05]$. For 24 items in turn $[\mathrm{r}=0.048$ $*, p=0.613>0.05]$. Correlation for 15, 20, 22 and 24 is positive at the level of very low. This shows there is a significant relationship between the inputs in the implementation of the SBA with teachers teaching experience. While for item 11 is $[\mathrm{r}=-0.042 *, \mathrm{p}=0.661>0.05]$. Item 12 is $[\mathrm{r}=-0.092$ $*, \mathrm{p}=0.333>0.05]$. Item 13 is $[\mathrm{r}=-0.132 *, \mathrm{p}=$
$0.167>0.05]$. Item 14 is $\left[\mathrm{r}=-0.122^{*}, \mathrm{p}=0.200>\right.$ $0.05]$. Item 16 is $[\mathrm{r}=-0.137, \mathrm{p}=0.149>0.05]$. Item 17 is $\left[\mathrm{r}=-0.135^{*}, \mathrm{p}=0.157>0.05\right]$. tem 18 is $[\mathrm{r}=-$ $0.162 *, p=0.088>0.05]$. Item 19 is $\left[\mathrm{r}=-0.061^{*}, \mathrm{p}\right.$ $=0.520>0.05]$. Item 21 is $[\mathrm{r}=-* 0.016, \mathrm{p}=0.867>$ $0.05]$. Item 23 is $[\mathrm{r}=-0.046, \mathrm{p}=0.631>0.05] .25$ items is $\left[\mathrm{r}=-0.040^{*}, \mathrm{p}=0.673>0.05\right]$. Correlation for items $11,12,13,14,16,17,18,19,21,23$, and 25 shows there is no significant relationship between the inputs in the implementation of the SBA with teachers teaching experience.

3. Pearson Correlation analysis result, in total there are 3 items that shows that there are significant relations and 7 items that show there is no significant relationship between the processes of the implementation of the SBA with teachers teaching experience. So it can be concluded that there is no significant relations in the process of the implementation of the SBA with teachers 
teaching experience. For item 32 results obtained from analysis is $[\mathrm{r}=0.016 * \mathrm{p}=0.865>0.05]$. Item 33 is $\left[\mathrm{r}=\right.$ Peter $\left.^{*}, \mathrm{p}=0.240>0.05\right]$. Item 35 is $[\mathrm{r}=$ $0.070, p=0.463>0.05]$. Correlation for items 32 , 33 and 35 is positive at low levels. This shows there is a significant relationship between the processes of the implementation of the SBA with teachers teaching experience. While for 26 items is $[\mathrm{r}=-0.091 *, \mathrm{p}=0.338>0.05]$. Item 27 is $[\mathrm{r}=-0.16$, $\mathrm{p}=0.864>0.05] .28$ item is $[\mathrm{r}=-0.005 *, \mathrm{p}=0.959$ $>0.05] .29$ items is $[\mathrm{r}=-0.059 *, \mathrm{p}=0.538>0.05]$. Item 30 is $[r=0.000, p=0.997>0.05]$. Item 31 is $[\mathrm{r}=-0.086 *, \mathrm{p}=0.366>0.05]$. Item 34 is $[\mathrm{r}=-$ $0.003, p=0.973>0.05]$. Correlation of item 26, 27, $28,29,30,31$ and 34 show that there is a significant relationship between the processes of the implementation of the SBA teachers teaching experience.

4. Pearson Correlation analysis results, in total there are 2 items that shows that there are significant relations and 8 items that show there is no significant relationship between the products of the implementation of the SBA with teaching experience teachers. It can be concluded that there is no significant relations in the product of the implementation of the SBA with teachers teaching experience. For 37 results obtained from analysis is $[\mathrm{r}=0.012 *, \mathrm{p}=0.900>0.05]$. Item 42 is $[\mathrm{r}=$ $0.041 *, \mathrm{p}=0.671>0.05]$. Correlation for items 37 and 42 is positive at low level. This shows there is a significant relationship between the product dimensions in the implementation of the SBA with teachers teaching experience. While for item 36 is $[\mathrm{r}=0.229 *, \mathrm{p}=0.015>0.05]$. Item 38 is $[\mathrm{r}=-$ $0.019, \mathrm{p}=0.318>0.05]$. Item 39 is $\left[\mathrm{r}=-0.097^{*}, \mathrm{p}\right.$ $=0.310>0.05]$. Item 40 is $\left[\mathrm{r}=-0.035^{*}, \mathrm{p}=0.712>\right.$ $0.05]$. Item 41 is $[r=-0.013, p=0.893>0.05]$. Item 43 is $[\mathrm{r}=-0.000 *, \mathrm{p}=1,000>0.05]$. Item 44 is $[\mathrm{r}=$ $\left.0.064-^{*}, \mathrm{p}=0.501>0.05\right]$. Item 45 is $[\mathrm{r}=-0.027, \mathrm{p}=$ $0.779>0.05]$. Correlation for items $36,38,39,40$, $41,43,44$ and 45 shows there is no significant relationship between the products of the implementation of the SBA with teachers teaching experience.

In conclusion, the findings indicate that there is no significant relationship between context, input, process and products in the implementation of the SBA with teachers teaching experience. This proves that the hypothesis of this study is accepted.

Research Question 3: To identify the advantages, weaknesses, challenges and recommendations in realizing the SBA science teacher.

The findings of research question 3 via the interview. Table 6 shows the profile of the respondents.

(a) What are the benefits of the implementation of the SBA in science?

Based on analysis of interviews with the five respondents can be deduced that SBA has its benefits. This is evident when all five of the respondents gave a positive answer to the implementation of the SBA in the subjects of science.
They agree that SBA has advantages such as SBA with the nation's aspirations to produce world-class human capital, giving freedom and autonomy to teachers of science to evaluate and assessing pupils according to the readiness and ability of pupils as teachers learn more about students, save costs because there is no need to print the examination questions and SBA. SBA is also in line with the philosophy of science education in Malaysia to foster a culture of science and technology with a focus on individual development of a competitive, dynamic, agile and resilient and able to master the knowledge of science and high technology.

Table 6: The respondent's profile

\begin{tabular}{|c|c|c|c|c|}
\hline Teacher & Sex & Race & Age & $\begin{array}{l}\text { Teaching } \\
\text { experience }\end{array}$ \\
\hline A & Female & Indian & 40 year & 17 years \\
\hline B & Female & Chinese & 25 year & 3 year \\
\hline $\mathrm{C}$ & Male & Indian & 27 year & 5 year \\
\hline D & Female & Malay & 45 year & 20 year \\
\hline$E$ & Male & Malay & 37 year & 14 year \\
\hline
\end{tabular}

(b) What are the weaknesses or lack of implementation of SBA in the subjects of science?

Based on interviews with all five of the respondents, they in agreement states among the main drawback SBA is still many teachers who do not know about the implementation of SBA as a whole. Liquidity information related to SBA is not going well. This resulted in teachers being unjust in giving an assessment to each student; in addition, the time constraints because the pursuit of measurement science cause teachers hard to implement.

(c) What suggestions for improvement in the implementation of the SBA?

Respondents suggest some methods to improve the implementation of the SBA. Among the most important the MOE to provide committed in furtherance of the SBA so there is quality assurance. The parties are advised always to ensure the liquidity of information related to SBA get directly to the teacher. There needs to be training, courses, monitoring, and ongoing support either in terms of planning and implementation process.

In conclusion, the results of analyses successfully answered all questions of the study that is; on the whole the level of dimensional context, input and the product is simple, while the dimensions of the process are high. The hypothesis of this study is also received in which pearson correlation analysis shows that there is no significant relations the dimension of context, input, process and products in the implementation of the SBA with teaching experience teachers. Based on analysis of interviews with five respondents found they agree that SBA has advantages such as SBA with the nation's aspirations to produce world-class human capital, give freedom and autonomy to teachers of science to evaluate and assessing pupils according to the readiness and ability of pupils as teachers learn more about students, save costs because there is no 
need to print the examination questions and SBA does not give pressure on the school to maintain the performance of the school and compete with other schools. However, they in agreement States among the main drawback SBA is still many teachers who do not know about the implementation of SBA as a whole. Liquidity information related to SBA are not going well. This resulted in teachers being unjust in giving an assessment to each student. In addition, the time constraints due to the pursuit of science subject syllabus resulted in teachers of science are hard to implement the SBA. They suggest the MOE to provide committed in furtherance of SBA so that there is quality assurance. The parties are advised always to ensure the liquidity of information related to SBA get directly to the teacher. There needs to be training, courses, monitoring and ongoing support either in terms of planning and implementation process.

What is most important is that all teachers involved in this study were very committed and have taken a positive approach to this latest policy on assessment. This study found that for these science teachers, the benefits that outweighed problems were that the implementation of SBA helps to develop positive attitudes, encourages personal progress, enhances collaborative skills and promotes creative teaching and learning activities.

\section{Conclusion}

In conclusion, although this study shows that the level of context, inputs and products SBA is still moderate, however the process is high. This shows that the implementation of the SBA can still be established or improved. In view of the School-Based Assessment (SBA) is a form of assessment of future education is also a heartfelt goodbye to the orientation of the examinations have been inviting criticism upon another. A paradigm shift is happening and this is in line with the orders of Sayidina Umar Al-Khatab who pointed out that the design of the children's education is required based on the needs of their future.

\section{Acknowledgment}

Sultan Idris Education University Research Grant.

\section{References}

Awang MI (2011). Pelaksanaan pentaksiran berasaskan sekolah: pengetahuan dan amalan guru di sekolah menengah agama milik kerajaan negeri. In the Seminar Majlis Dekan-dekan Pendidikan IPTA2011, Penang, Malaysia.
Azhari A (2005). Penilaian Program Pentaksiran Ujian Lisan Berasaskan Sekolah Bahasa Melayu SPM. M.Sc. Thesis, UKM Malaysia.

Barak M and Shakhman L (2008). Fostering higherorder thinking in science class: teachers' reflections. Teachers and Teaching: theory and practice, 14(3): 191-208.

Brown GT and Hirschfeld GH (2008). Students' conceptions of assessment: Links to outcomes. Assessment in Education: Principles, Policy and Practice, 15(1): 3-17.

Hogan, R. L. (2007). The Historical Development of Program Evaluation: Exploring the Past and Present. Online Journal of Workforce Education and Development, 2(4):1-14.

Kouritzin SG and Vizard C (1999). Feedback on feedback: Preservice ESL teachers respond to evaluation practices. TESL Canada journal, 17(1): 16-39.

Mahamod Z, Embi MA and Yusoff NMRN (2010). Pentaksiran Berasaskan Sekolah: Panduan untuk Guru Bahasa Melayu, Inggeris dan Arab. Penerbit Fakulti Pendidikan, UKM, Bangi, Malaysia.

Norazilawati A, Nik ANY, Rosnidar M (2012). Pelaksanaan Pendekatan Konstruktivisme Dalam Mata Pelajaran Sains. Universiti Pendidikan Sultan Idris. Jurnal Pendidikan Sains and Matematik Malaysia, 2(1):78-91.

Stufflebeam DL (1971). The use of experimental design in educational evaluation. Journal of Educational Measurement, 8(4): 267-274.

Stufflebeam DL (2002). CIPP evaluation checklist. A tool for applying the fifth installment of the CIPP model to assess long-term enterprises. Retrieved 11 July 2014, Available online at: http://www.wmich.edu/evalctr/checklists/cippc hecklist.htm

Stufflebeam DL (2003). The CIPP model for evaluation. Proceeding. In the Annual Conference of the Oregon Program Evaluators Network (OPEN), Portland, Oregon, USA.

Stufflebeam DL and Shinkfield AJ (2007). Evaluation. Theory, Models and Applications. Jossey-Bass, San Francisco, USA.

Tan AM (2010). Pentaksiran berasaskan sekolah (PBS) di Malaysia: kesediaan guru, isu, dan panduan pelaksanaan. Petaling Jaya, Gerakbudaya Enterprise, Selangor, Malaysia. 